\title{
ERRATUM
}

\section{Longitudinal Changes in Resting State Connectivity and White Matter Integrity in Adolescents With Sports-Related Concussion - Erratum}

Donna L. Murdaugh, Tricia Z. King, Binjian Sun, Richard A. Jones, Kim E. Ono, Andrew Reisner, AND Thomas G. Burns doi: 10.1017/S1355617718000413. Published online by Cambridge University Press on 24 August 2018.

The paper by Murdaugh et al. (2018) contains an error on page 781 that should be brought to the attention of readers. It is listed here, along with the incorrect and correct copy:

Incorrect copy: RECEIVED September 26, 2017; FINAL REVISION April 25, 2018; ACCEPTED April 26, 2018; FIRST PUBLISHED ONLINE August 24, 2018

Correct copy: RECEIVED September 26, 2017; FINAL REVISION April 25, 2018; ACCEPTED April 29, 2018; FIRST PUBLISHED ONLINE August 24, 2018

Cambridge University Press regrets the inconvenience that this error may have caused. The article has been updated with the correct copy. 